\title{
International Research \\ Collaboration and \\ International Research \\ Orientation: Comparative \\ Findings About European \\ Academics
}

Journal of Studies in International Education 2018, Vol. 22(2) 136-160

(C) 2017 European Association for International Education Reprints and permissions: sagepub.com/journalsPermissions.nav DOI: I0.II77/I0283I53I7747084 journals.sagepub.com/home/jsi

๑SAGE

\section{Marek Kwiek'}

\begin{abstract}
In this study, international research collaboration (IRC) and international research orientation (IRO) have been studied at the micro-level of individual academics from the university sector ( $N=8,466$, II European systems). Both were studied crossnationally, cross-disciplinarily, and cross-generationally. This study differs from most existing internationalization literature in its sample (Europe) and focus (patterns of internationalization in research), using more standard methods (a multivariate model approach). It addresses questions about the patterns of IRC and IRO, international publishing, and the predictors of IRC, or what makes some European academics more prone to collaborating with international colleagues in research than others. In the context of changing incentive and reward systems in European academic science, which are becoming more output oriented, it is ever more important for individual academics to cooperate internationally (as well as to co-publish internationally). "Internationalists" increasingly compete with "locals" in university hierarchies of prestige and for access to project-based research funding across Europe. Evidence is presented that co-authoring publications internationally is still a rare form of research internationalization in Europe (50.8\% of academics co-author publications internationally). However, as compared with other world regions, the percentage of European academics collaborating internationally in research $(63.8 \%)$ is very high. A striking cross-national differential within the youngest European generation of academics was found, which may be a strong barrier to intra-European research collaboration in the future.
\end{abstract}

\footnotetext{
'University of Poznan, Poland
}

\section{Corresponding Author:}

Marek Kwiek, Professor, Center for Public Policy Studies, Director, UNESCO Chair in Institutional Research and Higher Education Policy, University of Poznan, ul. Szamarzewskiego 89, Poznan 60-569, Poland.

Email: kwiekm@amu.edu.pl 


\section{Keywords}

Stratification in science, European academics, internationalists and locals, internationalization of research, cross-national publishing patterns, multivariate model approach, predictors of research collaboration

\section{Introduction}

International research collaboration (IRC) has captivated the imagination of the academic profession and organized the research policy steps taken by governments worldwide. Policy makers and funding agencies have encouraged IRC, in the expectation that it will produce higher impact rates in science and technology, foster publications, and improve the quality of training (Jeong, Choi, \& Kim, 2014; Landry \& Amara, 1998). European Union (EU) research funding programs and academic mobility programs enhancing IRC at a regional level have been present for two decades now. Although the world seems to collaborate in research mostly on nation-by-nation basis, Europe is exceptional in terms of its long-term, large-scale regional research collaborations (Georghiou, 1998; Hoekman, Frenken, \& Tijssen, 2010). Consequently, European academics should not only be highly involved in IRC but also exhibit high international research orientation (IRO).

Academic work can be viewed through academic attitudes (how academics perceive their work), academic behaviors (how they actually work), or both. A large data set with observations from 11 European countries $(N=17,211)$ enables us to refer to both attitudinal characteristics and actual behaviors from an international comparative perspective. Consequently, here, IRC is viewed as a specific academic behavior, and IRO is viewed as a specific academic attitude (Cummings \& Finkelstein, 2012; Kwiek, 2016). This study addresses four specific research questions: a behavioral question about the patterns of European academics' IRC; an attitudinal question about the patterns of IRO (both these questions are considered cross-nationally and cross-disciplinarily, and the latter is considered cross-generationally); a behavioral question about the patterns of international publishing, including international publication co-authorship (crossnationally and cross-generationally); and finally, a mixed attitudinal-behavioral question regarding the predictors of IRC, or what makes some academics more prone to collaborating with international colleagues in research than others, across Europe.

This research explores a single institutional type, the European university, across 11 countries and one subcategory of academics, academics employed full-time in the university sector and involved in both teaching and research. This article is structured as follows: "Previous Research"), "Method and Data Set", "IRC and IRO: CrossNational and Cross-Disciplinary Patterns", "Dimensions of International Publishing: Cross-National Patterns", "IRC and International Publication Co-authorship: CrossGenerational Patterns", and "Predictors of IRC-A Multivariate Model Approach". The final section presents the conclusions.

\section{Previous Research}

Academic disciplines and institutions affect the patterns of academic attitudes and behaviors at an individual level (Clark, 1983), in this case, the patterns of IRO and 
IRC, both of which are highly discipline sensitive. Previous research suggests that the "collaborative imperative" dominates, especially in hard disciplines, though it is less prevalent in soft ones (Kyvik \& Larsen, 1997; Lewis, 2013). In some disciplines, such as the humanities, the "lonely scholar" model dominates, whereas in others, only IRC, especially internationally co-authored publications, leads to academic recognition (Lewis, Ross, \& Holden, 2012) and, increasingly, access to national and international competitive research funding (Jeong et al., 2014; Melin, 2000). "Internationalists" or "cosmopolitans" (academics involved in IRC and/or publishing internationally) increasingly compete with "locals" (academics not involved in IRC and/or not publishing internationally) in university hierarchies of prestige across Europe (Wagner \& Leydesdorff, 2005; Kwiek, 2017a). Internationalists/cosmopolitans and locals are also competing for access to funding from national research funding agencies, especially in the hard sciences (Smeby \& Gornitzka, 2008).

Academics are central to the success of internationalization in research: They can be more or less (or not at all) internationally minded in their research. The imperative to internationalize is reported to be stronger in smaller and more peripheral countries. In theoretical approaches to IRO, the traditional "cosmopolitan/local" distinction has often been used. In Robert K. Merton's sociology of science (Merton, 1973), outstanding scientists tend to be "cosmopolitans," oriented to the wider "national and transnational environments," and "locals" tend to be oriented "primarily to their immediate band of associates" (p. 374). Alvin Gouldner (1957) in his "cosmopolitan-local" ideal types has contrasted academics who are more loyal to their employing organization and less research oriented (i.e., locals) with academics who are less loyal to their organization and more research oriented (i.e., cosmopolitans). Gouldner's data-based pure types of organizational loyalty and professional commitment have been reformulated in both organizational studies and higher education research (Abrahamson, 1965; Glaser, 1963; Rhoades, Kiyama, McCormick, \& Quiroz, 2008; Smeby \& Gornitzka, 2008). However, the distinction did not refer originally to internationalization in research (focusing on organizational roles and professional identities); the distinction connected to norms about professionals, including academics, with the concept of "mobility" in its center. Immobile, parochial, and institution-oriented academics (loyal to inside reference groups) were contrasted with mobile, cosmopolitan, career-oriented academics (loyal to outside reference groups) - in an American context of the midcentury rise of science and federal research funding (Abrahamson, 1965). Gouldner (1957) defined reference groups as those groups with which individuals identify and to whom they refer in making judgments about their own performance: Cosmopolitans and locals differ sharply in their identification. Their frame of reference in conducting research and publishing research results is fundamentally different, leading them to seeking different sources of recognition and to having different trajectories of academic careers (Wagner \& Leydesdorff, 2005).

The level of IRO differs across academic disciplines, soft sciences being, in general, more local, and hard sciences being more global or internationalized: Reward systems operate differently not only across countries but also across disciplines. In short, seeking international recognition within discipline-sensitive national reward systems in science may be more (or less) "necessary" (Kyvik \& Larsen, 1997, p. 260). The level of 
IRO depends also on what Richard Whitley (1984) termed "the structure of reputational audiences" (p. 220), different for different disciplines: Reputation comes from different audiences, lay groups, or groups of colleagues, national or international. Locals produce knowledge for local research markets and audiences; internationalists produce it for international markets and audiences, or both local and international ones (Kyvik \& Larsen, 1997). IRO is a function of individual propensity combined with disciplines, institutions, and national reward structures within science: Finally, at an individual level, IRO leads to a personal decision to internationalize more (or less) in research. The level of international orientation depends on the researchers themselves (Wagner \& Leydesdorff, 2005). Faculty internationalization is reported to be disproportionately shaped by deeply ingrained individual values and predilections, rather than institutions and academic disciplines (Finkelstein, Walker, \& Chen, 2013). Institutional-level pressures to internationalize - from a policy perspective - may not work.

The internationalists-locals distinction in research orientation has been analyzed under different rubrics, including the peripatetic-indigenous dichotomy (Welch, 1997) or the internationalists-insulars opposition (Cummings \& Finkelstein, 2012). However, the classical two-dimensional model of high commitment to research and high professional commitment (cosmopolitans) contrasted with high commitment to institution and high organizational loyalty (locals) leads also to different conceptualizations of IRO: Apart from pure cosmopolitans and pure locals in research, there can also be "mixed types" and "neither types" of academics - those combining international and local research orientation, and those generally uninterested in research (Grimes, 1980). There emerge two more classes: "local-cosmopolitan" scientists, on one hand, with dual orientation (Glaser, 1963); and "drones" or systematic nonproducers, with limited contribution to the overall academic enterprise (Harman, 1989), on the other. In an American context, the contrasted types of "local cosmopolitans" and "cosmopolitan locals" (Rhoades et al., 2008) in research offer alternative models of a professional, beyond the dichotomy of either strong IRO or strong local research orientation.

IRC is strongly correlated with IRO. Impediments to IRC are reported to be related to macro-level factors (geopolitics, history, language, cultural traditions, country size, country wealth, and geographical distance), institutional-level factors (reputation and resources), and individual-level factors (Georghiou, 1998; Luukkonen, Persson, \& Sivertsen, 1992). IRC patterns have been shown both in single-nation research and in global research (Wagner \& Leydesdorff, 2005). IRC has its benefits and its costs (Katz \& Martin, 1997). Specifically, transaction costs (Georghiou, 1998) and coordination costs (Cummings \& Kiesler, 2007) are higher in international than in national research collaboration. In collaborative research, national or international, there is a trade-off between an increase in additional publications and research funds and the minimization of transaction costs (Landry \& Amara, 1998). Having multiple universities involved in research collaboration complicates coordination and worsens the outcomes of projects (Cummings \& Kiesler, 2007). Research collaboration with highly productive scientists generally increases individual productivity, whereas collaboration with low-productivity scientists is reported to decrease it (Lee \& Bozeman, 2005). 
In the context of changing incentive and reward systems in European science, which are becoming more output oriented (Kyvik \& Aksnes, 2015), it is ever more important for individual academics to cooperate and, specifically, to cooperate internationally (as well as to co-publish internationally). Multiple-institution papers are more highly cited than single-institution papers, and papers with international coauthors are more highly cited than papers with domestic co-authors (Narin \& Whitlow, 1990). Performance-based funding modes are increasingly used across Europe, and the broad awareness of international research-based university rankings makes scholarly publishing more than an individual matter and links publications closely to institutional and/or departmental funding and prestige (Kwiek, 2017a). However, in highly competitive science systems, IRC may be primarily motivated by reward structures. As Wagner and Leydesdorff (2005) argued, "highly visible and productive researchers, able to choose, work with those who are more likely to enhance their productivity and credibility" (p. 1616).

IRC is the most demanding type of contact between researchers: "it presupposes attractiveness, international visibility, and often involves significant commitment by the researcher" (Smeby \& Gornitzka, 2008, p. 48). It also involves the entire research process (Smeby \& Trondal, 2005). Research collaboration at an individual level, both national and international, is reported to be ruled by researchers' "pragmatism" ("when there is something to gain, then a particular collaboration will occur; otherwise, it will not") and by their "self-organization" (individual rather than institutional determination of "with whom to cooperate and under which forms"; Melin, 2000, p. 39). IRC can be viewed as an emergent, self-organizing, and networked system. The selection of partners in IRC and locations for research is most often based on choices made by the researchers themselves. What matters in more spontaneous or bottom-up collaborations is "the individual interests of researchers seeking resources and reputation" (Wagner \& Leydesdorff, 2005, p. 1616).

According to resource allocation theory, the resources that academics and their teams can invest in research, in terms of their commitment and time, are always limited. Consequently, the decision to engage in research teamwork, including international research teamwork, "is ultimately a resource allocation decision by which members must decide how to best allocate their limited resources" (Porter, Itir Gogus, $\& \mathrm{Yu}, 2010$, p. 241), with time often being a more valuable research resource than funding (Katz \& Martin, 1997). The consumption of time due to various additional requirements can reduce the time and energy available for actual research activities (Jeong, Choi, \& Kim, 2011).

Research collaboration can be studied both between and within the individual, group, department, institution, sector, and national levels. In this research, following Katz and Martin (1997), IRC, at an individual level, means collaboration between academics located in different countries (and not between academics with different nationalities located in the same country or in the same institution), whereas intranational collaboration means collaboration within a single country. However, international collaboration rests upon a much larger base of domestic activities (Georghiou, 1998; Wagner, 2006). 
IRC can be either formal or informal (within or outside formal agreements and externally funded projects), and international publication co-authorship always requires a published product as an outcome of the cooperative efforts (Georghiou, 1998; Melin \& Persson, 1996). Not every IRC leads to internationally co-authored publications. There are many cases of collaborations that are not "consummated" in a co-authored paper (Katz \& Martin, 1997). The writing of co-authored papers does not necessarily imply a close relationship between the authors (Luukkonen et al., 1992). Traditionally, IRC has been dominated by informal collaboration, which does not require international scientific agreements (Georghiou, 1998). Scientists often "selfselect fellow collaborators . . . simply because the collaborator offers new ideas or complementary capabilities" (Wagner, 2006, p. 3).

This research is focused on IRC and assumes the researcher-based view rather than the research-based view (Jeong, Choi, \& Kim, 2011). Thus, the unit of analysis is the individual academic. Apart from the "solo research" mode in science, internal collaboration (within the same organization), domestic collaboration (within the same country), and international collaboration (between countries) must be clearly differentiated (Jeong, Choi, \& Kim, 2011, p. 969). Collaboration is largely a matter of social convention among scientists and, therefore, difficult to define; what constitutes a collaboration varies across organizational levels and changes over time (Katz \& Martin, 1997). Research collaboration can be defined as a "system of research activities by several actors related in a functional way and coordinated to attain a research goal corresponding with these actors' research goals or interests" (Laudel, 2002, p. 5). Thus, collaboration presupposes that a shared research goal is defined by activities rather than by the actors involved, and the term is reserved for research that includes personal interactions. Given this definition, collaboration need not be focused on publishing articles. Collaborations may have no publication objectives at any point. Broader notions of collaboration are not easy to measure, and therefore, many studies of research collaboration "begin and end with [a] co-authored publication" (Bozeman \& Boardman, 2014, pp. 2-3).

For IRC to emerge, two preconditions must be met: motivation on the part of the researcher and his or her attractiveness as a researcher to international colleagues (Kyvik \& Larsen, 1994; Wagner, 2006). The ability of any actor to join international research networks depends on his or her attractiveness as a partner (Wagner \& Leydesdorff, 2005). "Visibility is a basic condition for being potentially interesting to other scientists, but one also has to be attractive in order to be actively sought out by others" (Kyvik \& Larsen, 1994, p. 163).

Overall, the international dimension in research has been understudied ("less discussed and more assumed as a natural and implicit element"; de Wit, 2002, p. 96) in the international higher education stream of literature (see Deardorff, de Wit, Heyl, \& Adams, 2012). Although internationalization-related shifts in "research" come under the pillar of "internationalization at home" (Knight, 2012), the theme is largely undiscussed. The present article, through the concepts of IRO and IRC, intends to highlight this somehow neglected area, using theoretical insights from academic profession studies, sociology of science, and scientometrics. 


\section{Method and Data Set}

This research uses a micro-level (individual) approach and relies on the primary data collected from European academics in an internationally comparable format. A data set created (June 17, 2011, International Center for Higher Education Research Kassel) by two large-scale research projects on the academic profession: "Changing Academic Profession" (CAP) and "Academic Profession in Europe: Responses to Societal Challenges" (EUROAC) allows us to analyze IRC and IRO among European academics in a comparative quantitative context.

The data for this research were collected through a survey administered in 11 European countries. The 11 national data sets were cleaned, weighted, and merged into a single European data set, which is the most comprehensive cross-national source of data on academic views, attitudes, perceptions, and behaviors in Europe today. The total number of usable returned surveys in Europe was 17,211 $(N=17,211)$ and included between 1,000 and 1,700 returned surveys from all the countries studied, except for Poland, where the total number of responses was higher (Kwiek, 2015b). A subsample of European academics who were employed full-time in the university sector and involved in both teaching and research (49.1\%, or 8,466 observations) is used. Overall, simple random sampling, systematic sampling, and stratified random sampling methods were used, depending on the country (RIHE, 2008; Teichler \& Höhle, 2013). The quality of the data set is high (Teichler, Arimoto, \& Cummings, 2013; Teichler \& Höhle, 2013), and it has been widely used in academic profession studies.

About $60 \%$ of academics in the sample are male, and about $40 \%$ are female. About $60 \%$ come from hard academic fields, and about $40 \%$ come from soft academic fields. The age cohorts and academic experience cohorts are relatively evenly distributed. A sample description in terms of selected demographic characteristics is presented in Table 1.

Six major clusters of academic disciplines were studied: life sciences and medical sciences, physical sciences and mathematics, engineering, humanities and social sciences, professions (which included teacher training and education science; business and administration, economics; and law in the questionnaire), and other fields. Both inferential statistics and a multivariate model approach were used.

The exact questions regarding IRC and IRO in the survey were formulated as follows: "How would you characterize your research efforts undertaken during this (or the previous) academic year?-Do you collaborate with international colleagues?" (yes/no; question D1/4); "How would you characterize the emphasis of your primary research this (or the previous) academic year? - international in scope or orientation" (on a 5-point Likert-type scale between $1=$ very much and $5=$ not at all, with answers 1 and 2 combined, question D2/5; other options included "basic/theoretical," "applied/ practically oriented," "commercially oriented," "based in one discipline," and "multi/ interdisciplinary"). No explanation or guidance was given in any of the 11 countries regarding the terms "international," "research" (and its variants), "research international in scope or orientation," or "international collaboration in research." We did not want to complicate the academic profession survey with 400 variables. One limitation 
Table I. Sample Description: Frequencies of Selected Demographic Characteristics, Only Academics Employed in the University Sector and Involved in Both Teaching and Research, All II European Countries Combined.

\begin{tabular}{lcc}
\hline & $n$ & $\%$ \\
\hline Gender & & \\
Male & 5,102 & 62.1 \\
Female & 3,113 & 37.9 \\
Age & & \\
Below 35 & 1,699 & 20.8 \\
$35-44$ & 2,532 & 31.0 \\
$45-59$ & 2,876 & 35.4 \\
60 and more & 1,041 & 12.8 \\
Academic experience & \\
Less than 7 & & 29.2 \\
$7-15$ & 2,431 & 29.1 \\
16 and more & 2,422 & 41.7 \\
Academic fields & 3,476 & 42.9 \\
Soft & & 57.1 \\
Hard & 3,455 & \\
\hline
\end{tabular}

a"Academic experience" means the number of years since one's first full-time employment ("beyond research and teaching assistant in higher education/research sector").

of this approach is the survey instrument's inability to distinguish between IRC based on nationality (for instance, Polish and German academics working together at a Polish or German university) or location (for instance, two German academics working in different countries) or between different modes and intensities of IRC (from exchanging emails with international colleagues to attending international conferences and writing joint international project proposals). Consequently, the behavioral concept of international collaboration in research was measured crudely (yes or no), and different individual perceptions of internationalization were lumped together and averaged. International co-authorship and international publishing were also crudely measured (through self-declared percentages of peer-reviewed internationally coauthored journal articles and book chapters, regardless of publication numbers, so that the publishing patterns lump high research performers together with low research performers).

\section{Research Findings}

\section{IRC and IRO: Cross-National and Cross-Disciplinary Patterns}

IRC differs substantially from IRO: The former represents academic behaviors (studied together with international publishing patterns in this article) and the latter represents academic attitudes. However, it is useful to study their patterns concurrently. In 


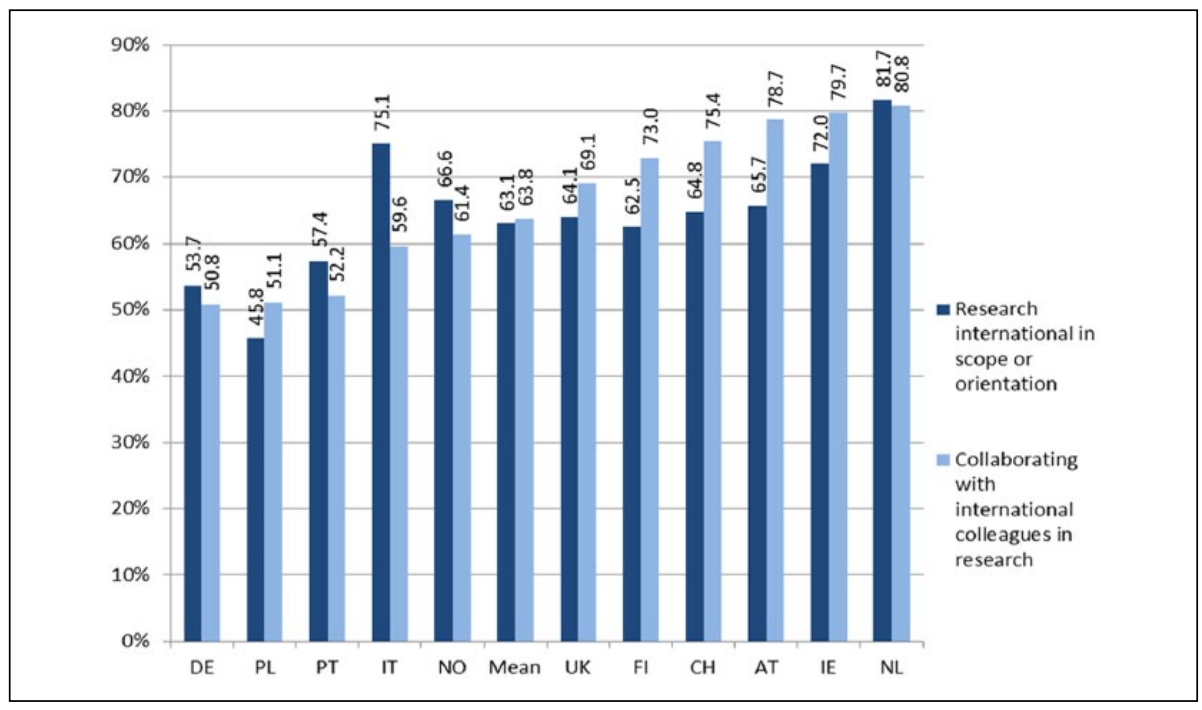

Figure I. Internationalization in research: Average percentage of academics whose research is international in scope or orientation and who collaborate in research with international colleagues, only academics employed in the university sector and involved in both teaching and research, by country.

terms of IRO, on average, about two thirds of academics characterize their primary research as "international" (63.1\%), with about three quarters of academics in Ireland, Italy, and the Netherlands and less than one half in Poland reporting this (Figure 1). In terms of IRC, on average, two thirds of academics collaborate internationally $(63.8 \%)$, with this number ranging from about one half in Poland, Germany, and Portugal to about three quarters in the Netherlands, Austria, Ireland, Switzerland, and Finland.

Two cases are interesting from a cross-national perspective. First, in Austria, Finland, and Switzerland, the percentage of internationally collaborating academics is considerably higher than the percentage of academics who view their research as international in scope or orientation, whereas in Italy, exceptionally in Europe, it is the other way around - The percentage of internationally collaborating academics is considerably lower than the percentage of academics who view their research as international in scope or orientation (by 15 percentage points). In most countries, the percentages of the attitudinal and the behavioral dimensions of internationalization are roughly similar. These two cases suggest that attitudes toward research internationalization can substantially differ from actual internationalization behaviors. The attitudinal concept of "international research" can have national variations in meaning, apart from cross-disciplinary differences (Kyvik \& Larsen, 1997). In most countries, internationalization attitudes match internationalization behaviors. In some countries, however, average real international collaboration is more common than average declared internationalization attitudes, and in Italy, real collaboration is substantially 


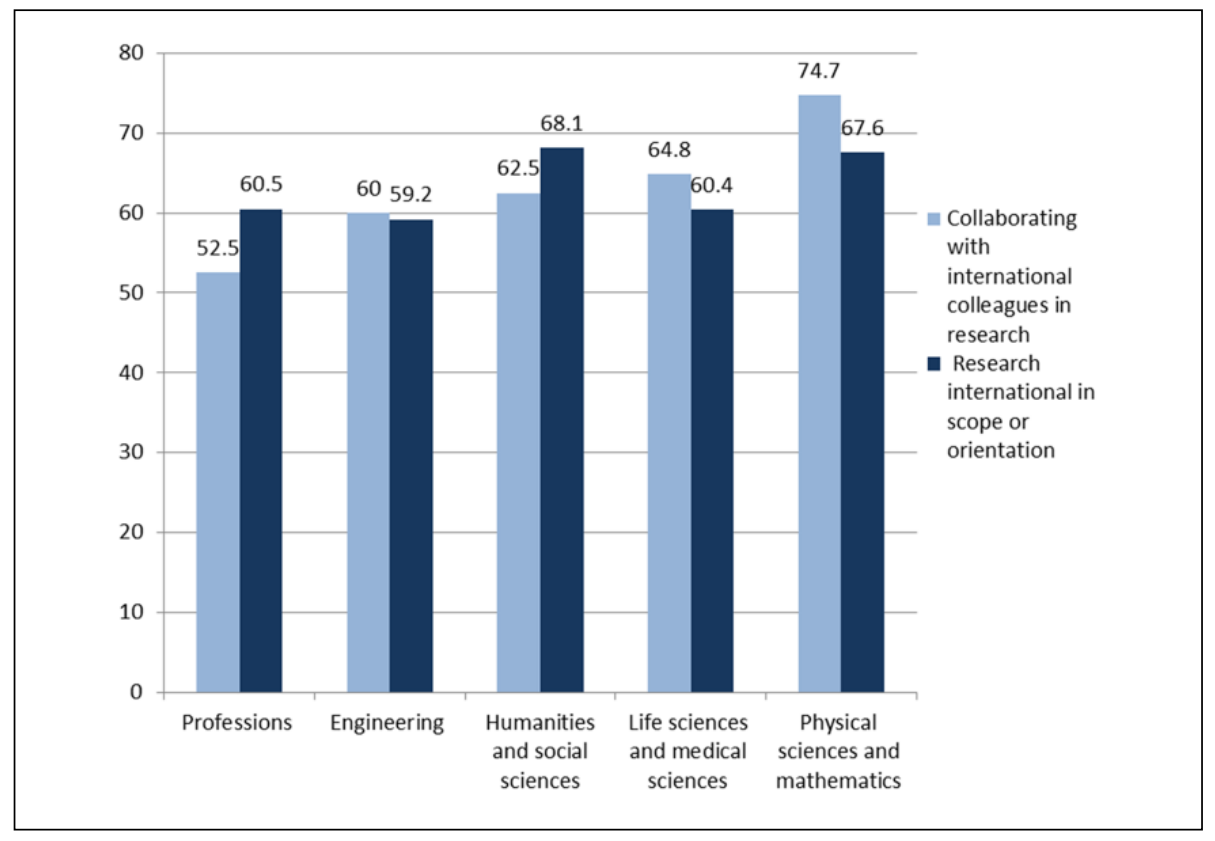

Figure 2. Internationalization in research: Percentage of academics whose research is international in scope or orientation and who collaborate in research with international colleagues, only academics employed in the university sector and involved in both teaching and research, by major clusters of academic fields.

less common than declared internationalization attitudes. The case of the Italian research internationalization has been discussed (Abramo, D'Angelo, \& Solazzi, 2011; Rostan, Ceravolo, \& Metcalfe, 2014), and our research confirms the previous findings, according to which the internationalization attitude/behavior discrepancy in Italy is high.

From a cross-disciplinary perspective, consistent with previous studies (Hoekman et al., 2010; Lewis, 2013; Rostan \& Ceravolo, 2015), in terms of IRC, academics in the physical sciences and mathematics are by far the most internationalized in research (with about three fourths being "internationalists"), and academics in professions are the least internationalized (with only about half of them being "internationalists," see Figure 2). Surprisingly, in light of previous studies, the level of research internationalization, as viewed through the proxy of international collaboration in research, is similar for the humanities and social sciences, on one hand, and engineering, life sciences, and medical sciences, on the other hand (with about $60 \%-65 \%$ of researchers in both categories being "internationalists"). However, in terms of IRO, interestingly, academics in the humanities and social sciences are, on average, slightly more internationalized than academics in the physical sciences and mathematics and substantially more internationalized than academics in the life sciences and medical sciences. 
Table 2. International Research Collaboration by International Research Orientation, Percent by Column, Only Academics Employed in the University Sector and Involved in Both Teaching and Research, All Countries Combined.

\begin{tabular}{|c|c|c|c|c|c|}
\hline & & \multicolumn{4}{|c|}{ Research international in scope or orientation } \\
\hline & & \multicolumn{2}{|c|}{ No } & \multicolumn{2}{|c|}{ Yes } \\
\hline & & $\%$ & Table \% & $\%$ & Table \% \\
\hline \multirow{2}{*}{$\begin{array}{l}\text { Collaboration in research with } \\
\text { international colleagues }\end{array}$} & No & 54.3 & 19.9 & 22.1 & 14.0 \\
\hline & Yes & 45.7 & 16.7 & 77.9 & 49.4 \\
\hline
\end{tabular}

Note. Column percent ( $\mathrm{I}$ and 3 separately) add to 100 . Table percent ( 2 and 4 together) add to 100. $\chi^{2}=778.12, p<.001$.

The disciplinary patterns of IRC and IRO are similar to the country patterns. In some disciplines, such as in the physical sciences and mathematics, a higher share of academics actually collaborate internationally than characterize their research as international. In others, notably in the humanities, social sciences, and professions, it is the other way around, leading to substantial cross-disciplinary differences in the understanding of what "international research" is. (The relationship between an international scope or orientation in research and major clusters of academic disciplines is statistically significant, with $\chi^{2}=49.4, p<.001$, as is the relationship between international collaboration in research and major clusters of academic disciplines, with $\left.\chi^{2}=122.4, p<.001\right)$.

Viewed through a double lens of IRC and IRO, European academics can be classified into four distinctive groups. Two of them - traditionally studied in research literature as "internationalists" or "cosmopolitans" or "globals"-and "locals" (Abrahamson, 1965; Finkelstein et al., 2013; Kyvik \& Larsen, 1997; Merton, 1973; Kwiek, 2015a)— are those who collaborate internationally and view their research as international in scope or orientation (answers yes and yes, about half of all academics, 49.4\%, see columns "Table \%" in Table 2) and those who do not collaborate internationally and do not see their research as international in scope or orientation (answers no and no, about one fifth of all academics, or 19.9\%). Our findings do not confirm Smeby and Gornitzka's (2008) claim about Norwegian academics that given the overall rise in IRC, the distinction between locals and cosmopolitans is no longer valid and we are "all cosmopolitans" (p. 37).

However, there are also two other groups, jointly comprising about $30 \%$ of European academics, which seem to complicate the, otherwise simple (and dichotomous), picture of research internationalization: those who collaborate internationally but do not view their research as international (answers yes and no, $16.7 \%$ of academics) and those who do not collaborate internationally but characterize their research as international (answers no and yes, $14.0 \%$ of academics). The relation between an international scope or orientation in research and international collaboration is statistically significant, with $\chi^{2}=778.12, p<.001$. Interesting tensions between internationalization in research in 
behavioral terms (collaboration that is actually undertaken) and in attitudinal terms (a characterization of the emphasis in research, regardless of the various research efforts undertaken) emerge. Certainly, cross-disciplinary differences emerge. In some disciplines, research can be not international in content but can still require international collaboration (for instance, in STEM [science, technology, engineering and mathematics] fields). In others, research can be international in content and can be conducted as solo research, with no international collaboration (for instance, in language studies or anthropology). IRC has always been most conveniently measured by international coauthorships, though there has been some criticism of equating the two (Katz \& Martin, 1997; Lee \& Bozeman, 2005).

Although, in very general terms, the traditional notion of "internationalists"/"cosm opolitans" and "locals" seems to capture the differences in various aspects of internationalization in research very well, when applied to a micro-level of individual academics and their self-declared academic attitudes and academic behaviors, these terms seem to miss almost one third of European academics. Consequently, a traditional dichotomous typology does not serve the European academic profession well. Apart from internationalists and locals, there are also academics who are involved in international collaboration (behaviors) but do not characterize their research as international (attitudes), as well as academics who are not involved in international collaboration but do characterize their research as international. Internationalists and locals represent pure types of academics in the sense that their academic attitudes roughly match their academic behaviors, and the latter two types represent mixed types in the sense that these two factors do not match. Our research findings will be more robust when cross-national patterns of internationalization are studied through academic behaviors - that is, IRC (and international publishing) — rather than IRO, or academic attitudes. This approach is adopted below in sections "Dimensions of International Publishing: Cross-National Patterns" and "IRC and International Publication Co-authorship: Cross-Generational Patterns."

\section{Dimensions of International Publishing: Cross-National Patterns}

Apart from a straightforward approach to IRC ("Do you collaborate with international colleagues?"), its three proxies are considered in this section: self-declared percentages of internationally co-authored publications, percentages of publications in international journals, and percentages of publications in English. Three thresholds were used: "at least 1\%" (very low intensity), "at least 25\%" (medium intensity), and "at least 50\%" (high intensity) of one's academic works. The 1\% threshold allows us to determine the share of academics who are effectively not involved in international publishing. The other two thresholds allow to see the intensity of international publishing from cross-national (and cross-generational in the next section) perspectives.

At the medium level of intensity, on average, about three quarters of European academics report publishing in a foreign language (74.1\%), about two thirds (63.9\%) report publishing in international journals, and about one third (28.9\%) report publishing in coauthorship with international colleagues (Table 3). Huge cross-national differentiation 
Table 3. International Publishing: Mean Percent of Academics Who Recently Co-authored Publications With Colleagues From Other Countries, Who Published in Foreign Journals, and Who Published in a Foreign Language (Only Academics Employed in the University Sector and Involved in Both Teaching and Research), by Level of Intensity and Country.

\begin{tabular}{|c|c|c|c|c|c|c|c|c|c|}
\hline \multirow{3}{*}{$\begin{array}{l}\text { Academics who have } \\
\text { recently... }\end{array}$} & \multirow{2}{*}{\multicolumn{3}{|c|}{$\begin{array}{c}\begin{array}{c}\text { Co-authored publications } \\
\text { with international colleagues }\end{array} \\
\begin{array}{c}\text { (by intensity } \\
\text { thresholds) }\end{array}\end{array}$}} & \multirow{2}{*}{\multicolumn{3}{|c|}{$\begin{array}{c}\text { Published in } \\
\text { international journals } \\
\text { (by intensity } \\
\text { thresholds) }\end{array}$}} & \multirow{2}{*}{\multicolumn{3}{|c|}{$\begin{array}{c}\begin{array}{c}\text { Published in a foreign } \\
\text { language }\end{array} \\
\text { (by intensity } \\
\text { thresholds) }\end{array}$}} \\
\hline & & & & & & & & & \\
\hline & $>1 \%$ & $>25 \%$ & $>50 \%$ & $>1 \%$ & $>25 \%$ & $>50 \%$ & $>1 \%$ & $>25 \%$ & $>50 \%$ \\
\hline Austria & 62.1 & 35.6 & 16.4 & 85.5 & 71.7 & 59.9 & 86.4 & 72.7 & 61.1 \\
\hline Finland & 46.9 & 26.3 & 12.4 & 76.7 & 64.9 & 53.8 & 79.8 & 69.9 & 59.3 \\
\hline Germany & 44.6 & 24.0 & 9.1 & 71.6 & 57.2 & 42.1 & 86.8 & 75.3 & 59.9 \\
\hline Ireland & 58.0 & 28.8 & 12.4 & 83.6 & 66.6 & 53.2 & - & - & - \\
\hline Italy & 43.5 & 21.3 & 9.9 & 66.8 & 55.4 & 46.3 & 79.2 & 67.3 & 58.4 \\
\hline Netherlands & 70.0 & 41.7 & 21.2 & - & - & - & 96.6 & 90.2 & 82.5 \\
\hline Norway & 47.0 & 29.6 & 13.0 & - & - & - & 93.1 & 85.3 & 74.5 \\
\hline Poland & 25.4 & 24.1 & 12.3 & 77.3 & 67.6 & 57.6 & 74.0 & 71.8 & 50.7 \\
\hline Portugal & 47.7 & 25.7 & 8.8 & 60.4 & 58.7 & 38.9 & 75.7 & 65.9 & 48.1 \\
\hline Switzerland & 65.4 & 38.6 & 19.4 & 78.7 & 68.3 & 51.9 & 79.7 & 68.6 & 57.1 \\
\hline The United Kingdom & 48.5 & 22.3 & 7.7 & 77.5 & 64.4 & 55.2 & - & - & - \\
\hline Total & 50.8 & 28.9 & 13.0 & 75.3 & 63.9 & 51.0 & 83.5 & 74.1 & 61.3 \\
\hline
\end{tabular}

Note. In the Netherlands and Norway, the question about publishing in international journals was not asked. In Ireland and the United Kingdom, the foreign language question was excluded from the analysis. The questions were as follows: "Which percentage of your publications in the last three years were co-authored with colleagues located in other (foreign) countries" (D5/3), "published in a foreign country" (D5/4), and "published in a language different from the language of instruction at your current institution" (D5/I).

applies, with the Netherlands and Switzerland showing the highest shares of internationally co-authored publications at both the medium- and the high-intensity levels (about $40 \%$ and $20 \%$ ), far above the European averages. Not surprisingly, given the low public and private funding for research and high teaching loads, the country with the highest share of academics not co-authoring publications with international colleagues is Poland (about three quarters, with the European average being about 50\%).

This research shows a striking difference between the three modes of international publishing: publishing in a foreign language and in a foreign country, on one hand, and co-authoring publications with international colleagues, on the other. The latter type of publishing, consistent with the prior literature (Melin \& Persson, 1996; Smeby \& Gornitzka, 2008), is a much rarer form of research internationalization in Europe. About one half of academics (49.2\%) did not co-author any publications internationally within the 3-year reference period, and on average, about one in four of them (28.9\%) co-authored his or her publications internationally with a medium level of intensity, and about one in eight $(13.0 \%)$ co-authored his or her publications with a high level of intensity (Table 2). Compared with other world regions, the percentage of academics collaborating internationally in research (63.8\%), as well as publishing 
Table 4. International Research Collaboration: Percent of Academics Collaborating Internationally in Research (Only Academics Employed in the University Sector and Involved in Both Teaching and Research), by Country and Academic Cohort (the Year Range of the First Academic Job).

\begin{tabular}{|c|c|c|c|c|}
\hline & $2001-2010$ & $|99|-2000$ & $198 \mid-1990$ & Before 1981 \\
\hline & $\%$ & $\%$ & $\%$ & $\%$ \\
\hline Austria & 70.4 & 80.9 & 86.7 & 85.9 \\
\hline Finland & 64.4 & 77.1 & 87.0 & 87.5 \\
\hline Germany & 39.0 & 56.2 & 72.2 & 63.9 \\
\hline Ireland & 80.4 & 76.6 & 81.2 & 77.4 \\
\hline Italy & 61.3 & 65.6 & 60.3 & 52.5 \\
\hline Netherlands & 80.7 & 82.4 & 81.3 & 76.8 \\
\hline Norway & 53.5 & 60.5 & 67.7 & 75.8 \\
\hline Poland & 45.4 & 47.3 & 57.9 & 55.3 \\
\hline Portugal & 43.8 & 54.6 & 60.5 & 72.7 \\
\hline Switzerland & 69.1 & 93.2 & 90.7 & 82.6 \\
\hline $\begin{array}{l}\text { The United } \\
\text { Kingdom }\end{array}$ & 77.6 & 60.5 & 84.2 & 55.1 \\
\hline Total & 62.3 & 68.6 & 75.4 & 71.4 \\
\hline
\end{tabular}

internationally and co-authoring publications internationally, is very high (Finkelstein et al., 2013, on the United States; Rostan, Finkelstein, \& Huang, 2014, on mature and emerging countries).

\section{IRC and International Publication Co-authorship: Cross-Generational Patterns}

IRC varies not only by country and discipline but also by academic generation. Academics enter universities in different eras and, thus, encounter different career opportunities and academic norms. A general change in the norms of appropriate academic behavior in which international collaboration figures prominently would contribute to explaining changes in productivity and collaboration patterns across all academic generations (Kyvik \& Aksnes, 2015). A cross-generational perspective complements traditional perspectives - cross-national, cross-institutional, and cross-disciplinary. A cohort approach to the academic profession has had limited use thus far (see Marquina \& Jones, 2015; Shin, Arimoto, \& Cummings, 2014; Jung, Kooij, \& Teichler, 2014; Kwiek 2015c; and Kwiek, 2017b).

From a cross-generational comparative perspective, in most of the countries studied, the highest share of academics collaborating with international partners in research is among older and oldest generations (see Table 4). Not surprisingly, in the context of existing single-nation literatures (Kyvik \& Larsen, 1997; Smeby \& Gornitzka, 2008), IRC needs time to grow and certainly needs access to funding, which increases with age (Jeong et al., 2014). 
Table 5. International Publication Co-authorship: Percent of Academics Who Have Recently Co-authored Publications With Colleagues in Other Countries, Only Academics Employed in the University Sector and Involved in Both Teaching and Research, by Country and Academic Cohort (the Year Range of First Academic Job).

\begin{tabular}{|c|c|c|c|c|c|c|c|c|}
\hline & \multirow{2}{*}{\multicolumn{2}{|c|}{$\begin{array}{c}\begin{array}{c}\text { Academic } \\
\text { generation } \\
2001-2010\end{array} \\
\begin{array}{c}\text { (by intensity } \\
\text { threshold) }\end{array}\end{array}$}} & \multirow{2}{*}{\multicolumn{2}{|c|}{$\begin{array}{c}\text { Academic } \\
\text { generation } \\
\text { |99|-2000 } \\
\text { (by intensity } \\
\text { threshold) }\end{array}$}} & \multirow{2}{*}{\multicolumn{2}{|c|}{$\begin{array}{c}\text { Academic } \\
\text { generation } \\
\text { 198I-1990 } \\
\begin{array}{c}\text { (by intensity } \\
\text { threshold) }\end{array}\end{array}$}} & \multirow{2}{*}{\multicolumn{2}{|c|}{$\begin{array}{c}\begin{array}{c}\text { Academic } \\
\text { generation } \\
\text { before } 1981\end{array} \\
\begin{array}{c}\text { (by intensity } \\
\text { threshold) }\end{array}\end{array}$}} \\
\hline & & & & & & & & \\
\hline & $>25 \%$ & $>50 \%$ & $>25 \%$ & $>50 \%$ & $>25 \%$ & $>50 \%$ & $>25 \%$ & $>50 \%$ \\
\hline Austria & 35.5 & 16.7 & 39.3 & 20.1 & 35.9 & 14.5 & 25.8 & 10.7 \\
\hline Finland & 21.4 & 11.2 & 27.7 & 13.9 & 32.5 & 14.1 & 25.5 & 9.8 \\
\hline Germany & 23.2 & 9.9 & 27.6 & 9.7 & 18.0 & 6.0 & 24.3 & 7.4 \\
\hline Ireland & 31.4 & 13.6 & 26.8 & 12.4 & 19.4 & 9.0 & 28.6 & 10.2 \\
\hline Italy & 21.2 & 11.4 & 27.1 & 11.3 & 22.7 & 10.6 & 14.0 & 6.8 \\
\hline Netherlands & 51.0 & 27.9 & 44.6 & 24.1 & 33.1 & 13.3 & 31.0 & 13.1 \\
\hline Norway & 31.5 & 13.4 & 27.9 & 14.0 & 29.6 & 12.2 & 30.8 & 10.7 \\
\hline Poland & 20.1 & 8.9 & 20.0 & 12.3 & 24.7 & 12.2 & 30.6 & 16.0 \\
\hline Portugal & 29.0 & 9.3 & 25.5 & 9.8 & 21.6 & 5.7 & 31.6 & 9.0 \\
\hline Switzerland & 40.2 & 22.1 & 38.5 & 17.9 & 51.7 & 19.0 & 33.5 & 23.1 \\
\hline The United Kingdom & 18.0 & 8.7 & 23.8 & 7.3 & 34.3 & 13.1 & 11.8 & 0.0 \\
\hline
\end{tabular}

In none of the countries studied was the share of internationally collaborating academics the highest for the youngest academic cohort, those who had entered the profession since 2001 (consistent with Jung et al.'s, 2014, global conclusion that senior academics' careers appear to be more international than those of junior academics). Substantial cross-country differences apply, however. By far, the least internationalized oldest generation of the academic profession in Europe exists in the United Kingdom, Poland and Italy, with slightly more than half of academics collaborating internationally, and the least internationalized youngest generation of the academic profession in Europe exists in Germany, Poland, and Portugal (Table 4). There is an interesting difference between these three countries and the Netherlands, Ireland, and the United Kingdom, where the share of internationalists among the youngest generation reaches $80 \%$, as compared with $40 \%$ to $45 \%$ for the former. Country size explains the Dutch case (small systems tend to cooperate internationally more frequently than larger ones; Kyvik \& Larsen, 1997; Smeby \& Trondal, 2005), but this does not explain the Portuguese case, which is an equally small system (as opposed to the Polish and German cases, which represent relatively large higher education systems and internal research and publication markets).

Applying a generational approach to international co-authorship leads to the following results (Table 5): There are clearly three European countries in which the youngest academic generations (those entering university employment from 2001 to 2010), at both the medium and high publication intensity levels, have the highest share 
of internationally co-authored publications. The leaders in this regard are the Netherlands and Switzerland, followed by Austria. In terms of international co-authorship, the least internationalized systems among the youngest academic generation are Germany, Poland, Italy, Finland, and the United Kingdom.

\section{Predictors of IRC - A Multivariate Model Approach}

Finally, in an attempt to explain IRC, a multivariate model approach is adopted in this section. The predictors of IRC are explored. The research literature on IRC based on the core CAP/EUROAC data set is scarce, and its geographical focus is global or single nation (Finkelstein et al., 2013; Jung et al., 2014; Rostan \& Ceravolo, 2015; Rostan et al., 2014). The choice of independent variables was guided by conceptual frameworks that had already been applied to the core data set, along with some modifications. The modifications included the use of independent variables that were relevant in the European context, as well as a focus on a subset of institutions (universities only), a subset of academics (employed full-time and involved in both teaching and research activities), and international collaboration as a straightforward dichotomous dependent variable.

The decision to collaborate internationally in research is always made by an individual academic working in an academic institution in a national setting. In general, following Blackburn and Lawrence's (1995) work on academic activities, the individual and contextual factors involved in the shaping of international activities of European academics were combined in the model. Clark's (1983) matrix shows academic work to be embedded in institutional types and academic disciplines. However, in this model, only a single institutional type, the European university, was explored. Six clusters of academic disciplines were used. The relevant factors included individual biographical features, organizational and professional features, and structural/contextual (country-related) features characterizing the wider context within which international research activities are performed (see a global analysis in Rostan \& Ceravolo, 2015).

The intensity of IRC tends to differ by the type of research conducted. The survey instrument used allowed us to characterize one's primary research emphasis as either basic/theoretical or applied/practically oriented, with intensity being measured on a 5-point Likert-type scale from very much to not at all. At the level of individual variables, gender; age, through the proxy of academic cohorts (Jung et al., 2014); and father's tertiary education, as a proxy of the social and cultural capital provided by academics' families, were used. Also, a single predictor related to socialization within academia (earning a doctoral degree abroad) and a single predictor related to the academic profession (the academic rank of the professor) were used. Finally, three independent variables related to national contexts were used: The countries studied were classified as English speaking or non-English speaking; as small, medium, or large in terms of population size (Kyvik \& Larsen, 1997); and as lower, middle, or high in terms of their economic status or wealth (Luukkonen et al., 1992), as summarized in Table 6. 
Table 6. National Contextual Variables: Population and Wealth.

\begin{tabular}{|c|c|c|c|}
\hline \multicolumn{3}{|c|}{ Population (2017) } & GDP per capita (2016) \\
\hline Small & $\begin{array}{l}<15 \text { million: Austria, Finland, } \\
\text { Ireland, Norway }\end{array}$ & Lower & $<$ US\$20,000: Poland \\
\hline Medium & $\begin{array}{l}\text { I5-40 million: Poland, the } \\
\text { Netherlands }\end{array}$ & Middle & $\begin{array}{l}\text { US } \$ 20,000-50,000: \text { Austria, } \\
\text { Germany, Finland, Italy, the } \\
\text { Netherlands, the United Kingdom }\end{array}$ \\
\hline Large & $\begin{array}{l}\text { >40 million: Germany, Italy, } \\
\text { the United Kingdom }\end{array}$ & High & $>$ US $\$ 50,000$ : Ireland, Norway \\
\hline
\end{tabular}

Note. GDP = gross domestic product.

The logistic regression results for the dependent variable "collaborates with international colleagues in research" (yes-no dichotomy) are presented below. The independent variables were dichotomized through a recoding procedure; some variables were inherently dichotomous (male/female: yes or no; $\mathrm{PhD}$ achieved abroad: yes or no, etc.). Pearson rho's correlation tests were used to find significantly correlated predictors of the dependent variable. Large intercollerations among the predictors (multicollinearity) were tested using an inverse correlation matrix because a correlation matrix refers only to pairwise correlations of independent variables. Also, principal component analysis (PCA) was performed to determine whether any variables, due to their high levels of correlation, could be grouped into homogeneous groups. No significant interdependence between any of the variables was found. The relevant reference categories selected in the model were as follows: belonging to "other" academic disciplines, an emphasis on "applied" research, being a female academic, belonging to the oldest academic cohort (entering the academic profession before 1981), one's father's education being "non-tertiary," not earning a $\mathrm{PhD}$ abroad, not being a professor, working in a large country, and working in a country with a high level of economic status.

Table 7 shows the logistic regression results for the dependent variable, controlling for the above independent variables. In the block of variables representing academic fields, academics working in the cluster of physical sciences and mathematics are more likely to collaborate with international colleagues in their research (consistent with Rostan, Ceravolo, \& Metcalfe's findings, 2014, and Cummings \& Finkelstein's findings, 2014), and those working in the professions cluster are less likely to collaborate as compared with "other disciplines" (here and in each case below, ceteris paribus). For the other clusters, the results are statistically insignificant. In the block of variables representing research emphasis, only the combined (both basic and applied) variable is statistically significant, and engaging in combined research significantly increases the odds of IRC as compared with an emphasis on applied research only. Gender emerges as highly correlated with IRC (consistent with Rostan et al., 2014, and inconsistent with Cummings and Finkelstein's U.S. case, 2014). Being male significantly, $\operatorname{Exp}(B)=1.69$, increases the odds of IRC as compared with being female, as does having entered the academic profession between 1981 and 1990, increasing 
Table 7. Predictors of International Research Collaboration, Only Academics Employed in the University Sector and Involved in Both Teaching and Research.

\begin{tabular}{|c|c|c|c|c|}
\hline & $B$ & $S E$ & Significance & $\operatorname{Exp}(B)$ \\
\hline \multicolumn{5}{|l|}{ Academic field } \\
\hline \multicolumn{5}{|l|}{ Life sciences and medical sciences } \\
\hline Physical sciences and mathematics & $0.489 * *$ & 0.148 & .001 & $1.63 * *$ \\
\hline \multicolumn{5}{|l|}{ Engineering } \\
\hline \multicolumn{5}{|l|}{ Humanities and social sciences } \\
\hline Professions & $-0.589 * * *$ & 0.145 & .000 & $0.555^{* * *}$ \\
\hline \multicolumn{5}{|l|}{ Other-reference category } \\
\hline \multicolumn{5}{|l|}{ Research emphasis } \\
\hline \multicolumn{5}{|l|}{ Basic } \\
\hline Combined & $0.392 * * *$ & 0.085 & .000 & $1.48^{* * *}$ \\
\hline \multicolumn{5}{|l|}{ Applied_reference category } \\
\hline \multicolumn{5}{|l|}{ Gender } \\
\hline Male & $0.525^{* * *}$ & 0.067 & .000 & $1.69 * * *$ \\
\hline \multicolumn{5}{|l|}{ Female-reference category } \\
\hline \multicolumn{5}{|l|}{ Academic cohort } \\
\hline \multicolumn{5}{|l|}{$2001-2010$} \\
\hline \multicolumn{5}{|l|}{$199 \mid-2000$} \\
\hline $1981-1990$ & $0.395^{* *}$ & 0.115 & .001 & $1.484 * *$ \\
\hline \multicolumn{5}{|l|}{ Before 1981-reference category } \\
\hline \multicolumn{5}{|l|}{ Father's education } \\
\hline \multicolumn{5}{|l|}{ Tertiary } \\
\hline \multicolumn{5}{|l|}{ Non-tertiary-reference category } \\
\hline \multicolumn{5}{|l|}{ PhD achieved abroad } \\
\hline Yes & $-0.381 * * *$ & 0.073 & .000 & $0.683 * * *$ \\
\hline \multicolumn{5}{|l|}{ No_reference category } \\
\hline \multicolumn{5}{|l|}{ Professor } \\
\hline Yes & $-0.866 * * *$ & 0.112 & .000 & $0.421 * * *$ \\
\hline \multicolumn{5}{|l|}{ No_reference category } \\
\hline \multicolumn{5}{|l|}{ English-speaking country } \\
\hline Yes & $-0.768 * * *$ & 0.118 & .000 & $0.464 * * *$ \\
\hline \multicolumn{5}{|l|}{ No_reference category } \\
\hline \multicolumn{5}{|l|}{ Country size } \\
\hline Small & $0.815^{* * *}$ & 0.097 & .000 & $2.259 * * *$ \\
\hline \multicolumn{5}{|l|}{ Medium } \\
\hline \multicolumn{5}{|l|}{ Large-_reference category } \\
\hline Country's economy status & & & & \\
\hline Lower & & & & \\
\hline Middle & $0.478 * * *$ & 0.105 & .000 & $1.613^{* * * *}$ \\
\hline High-reference category & & & & \\
\hline Constant & $1.006 * * *$ & 0.222 & .000 & $2.736 * * *$ \\
\hline
\end{tabular}

$* * * p<0.001 ; * * p<0.01 ; * p<0.05$. 


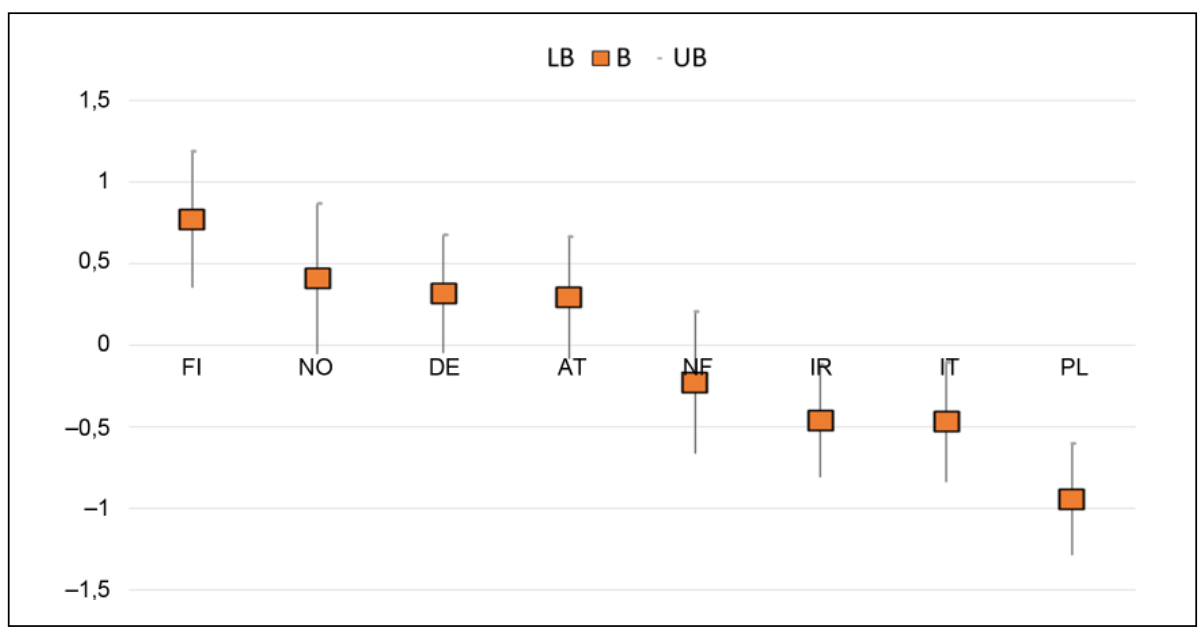

Figure 3. Net effect of the country of current employment on the odds of collaborating with international colleagues in research.

Note. B coefficients for countries with $95 \%$ confidence intervals. Only academics employed in the university sector and involved in both teaching and research.

the odds by about $40 \%$ as compared with the oldest academic generation. As an individual variable, one's father's education emerged as a statistically insignificant predictor. Surprisingly, the only academic socialization variable used in the model, defined as earning a PhD abroad - decreases the odds of IRC (consistent with Kyvik and Larsen's, 1997, findings), as does the academic profession variable of rank, with being a full professor decreasing the odds of IRC. Results from a multivariate model approach are consistent with results from a cross-generational section, assuming that professors belong mostly to the oldest generation in most European systems.

Finally, the three contextual (country-related) variables entered the equation. Consistent with previous literature, being an academic in an English-speaking country (Ireland and the United Kingdom in the sample) decreases the likelihood of IRC. Being an academic in a small country (with a small higher education system) radically increases the odds of IRC (the small countries in the sample being Austria, Finland, Ireland, and Norway). Finally, working in a country located in the middle of the wealth scale (as measured by GDP [gross domestic product] per capita) also increases the odds of IRC as compared with working in a high-income country.

In the next step of analysis, the contextual variables of language, country size, and country wealth were removed from the model, and nine countries were added, with the United Kingdom acting as a reference country (globally, see Rostan et al., 2014). The logistic regression results from this model do not differ substantially from the results of the first model. What did prove useful, however, was further exploring the block of country variables. The net effect of the country of current employment on the odds of collaborating with international colleagues in research is presented in Figure 3 in the 
form of $B$ coefficients of logistic regression for each country (the yellow squares are the $B$ coefficients). The major finding is a clear contrast between Finland and Poland, even though both countries are located on the global "scientific periphery" (Kyvik \& Larsen, 1997; Kwiek, 2016) due to their languages and their small "national scientific size" (Luukkonen et al., 1992). Academics working in Finland are more than twice, $\operatorname{Exp}(B)=2.158$, as likely to collaborate with international colleagues in research as compared with their colleagues from the United Kingdom, and academics working in Poland are less than half as likely to do so as compared with those in the United Kingdom, $\operatorname{Exp}(B)=0.389$. Poland and Finland are at two visible extremes in Figure 3 . This difference may be linked to divergent research policies over the last two decades, with a focus on internationalization in research in Finland and the long-term "deinstitutionalization" of the research mission in Polish universities and their persistent underfunding regarding research (Kwiek, 2012). Also, working in Ireland or Italy decreases the odds of collaborating internationally. For all other countries, the model does not yield statistically significant estimates (see the $95 \%$ confidence interval for the mean: lower and upper band crossing the zero line for Norway, Germany, Austria, and the Netherlands).

\section{Conclusion}

In this article, IRC and IRO have been studied at the micro-level of individual academics from the university sector $(N=8,466,11$ European systems). Both were studied cross-nationally, cross-disciplinarily, and cross-generationally, or by country, cluster of academic discipline, and academic generation. This article differs from most existing internationalization-related literature in that it is focused on the internationalization of academic research, rather than the internationalization of higher education from a cross-country comparative perspective (de Wit, 2002) or international higher education (Deardorff et al., 2012). It differs from most existing literature in its sample (Europe) and focus (the individual academic as a unit of analysis and patterns of internationalization in research, respectively), using more standard methods (a multivariate model approach).

The factors influencing internationalization are becoming increasingly, the research-based competition for major world rankings being a prime example. The traditional international cooperation and exchange is becoming overshadowed by "competition for status, bright students, talented faculty, research grants, and memberships in networks" (Knight, 2010, p. 211). And, status and recognition are granted to academics and academic institutions primarily through research outcomes - prestigious publications and grants alike, especially international (prestige-generating activities increasing academic salaries across Europe, Kwiek, 2017a). Assuming that internationalization-related shifts in "research" come under the pillar of "internationalization at home" (Knight, 2012), the concepts of IRO and IRC were discussed, using theoretical insights from international academic profession studies, sociology of science, and scientometrics. 
Evidence was presented that co-authoring publications internationally is a rare form of research internationalization in Europe as compared with publishing in a foreign language or in a foreign country. About half of European academics (50.8\%) coauthor publications internationally, and on average, about one in four $(28.9 \%)$ does so with a medium level of intensity, and about one in eight (13.0\%) does so with a high level of intensity or internationally co-author at least one quarter and one half of his or her work, respectively. As compared with other world regions, the percentage of European academics collaborating internationally in research (63.8\%), as well as publishing in international journals, publishing in a foreign language, and co-authoring publications internationally at the medium- and high-intensity levels, is very high (Huang, Finkelstein, \& Rostan, 2014; Rostan \& Ceravolo, 2015).

From a cross-generational perspective, rarely used in comparative IRC studies (Jung et al., 2014), in none of the 11 countries studied was the share of internationally collaborating academics the highest for the youngest cohort. At the same time, a striking cross-national differential within the youngest European generation of academics was found, with the share of internationally collaborating academics ranging from $80 \%$ (in the Netherlands, Ireland, and the United Kingdom) to 40\% (in Germany, Poland, and Portugal). This cross-national differential among new entrants into the academic profession may be a strong barrier to intra-European research collaboration in the future.

Finally, the predictors of IRC have been explored using a multivariate model approach. Cross-disciplinary variations in IRC emerged as substantial, with academics in the physical sciences and mathematics cluster and academics combining basic and applied research being more likely to collaborate internationally. Gender emerged as highly correlated with IRC. Being male significantly increased the odds of IRC (by $69 \%$ ) as compared with being female, which has heavy institutional policy implications for academic careers. Being an academic in an English-speaking country decreases the likelihood of IRC, and being an academic in a small country radically increases the likelihood of IRC. Also, working in less affluent European countries increases the odds of IRC as compared with working in high-income countries. The findings regarding the negative impact of having an international doctoral degree and being a full professor, although somewhat counterintuitive in both U.S. and global contexts, can be explained by some degree of discrepancy between one's current academic location and the location where one's socialization to academia occurred and by generally older age of professors (and the entire graying academic profession) in Europe as compared with the global average.

IRC and IRO are critically important in European academia given newly emergent university hierarchies of prestige, academic incentive and reward systems, and gradually redefined access to competitive research funding. Enhanced IRC, especially that leading to international publishing in top-tier journals, contributes to the emergence of new stratification in the European academic profession along the divide between internationalists and locals. From a global perspective, Europe is a highly interesting case because the IRC across the continent is not only programmatic in major EU and national-level research policy documents but also massively funded from national and EU sources. 


\section{Acknowledgment}

The support of Dr. Wojciech Roszka is gratefully acknowledged.

\section{Declaration of Conflicting Interests}

The author(s) declared no potential conflicts of interest with respect to the research, authorship, and/or publication of this article.

\section{Funding}

The author(s) disclosed receipt of the following financial support for the research, authorship, and/or publication of this article: The author gratefully acknowledges the support of the National Ministry of Science and Higher Education through its Dialogue grant 0021/DLG/2016/10 (EXCELLENCE).

\section{ORCID iD}

Marek Kwiek (iD) https://orcid.org/0000-0001-7953-1063

\section{References}

Abrahamson, M. (1965). Cosmopolitanism, dependence-identification, and geographical mobility. Administrative Science Quarterly, 10, 98-106.

Abramo, G., D'Angelo, C. A., \& Solazzi, M. (2011). The relationship between scientists' research performance and the degree of internationalization of their research. Scientometrics, 86 , 629-643.

Blackburn, R. T., \& Lawrence, J. H. (1995). Faculty at work: Motivation, expectation, satisfaction. Baltimore, MD: Johns Hopkins University Press.

Bozeman, B., \& Boardman, C. (2014). Research collaboration and team science: A state-ofthe-art review and agenda. Cham, Switzerland: Springer.

Clark, B. (1983). The higher education system: Academic organization in cross-national perspective. Berkeley: University of California Press.

Cummings, J. N., \& Kiesler, S. (2007). Coordination costs and project outcomes in multi-university collaborations. Research Policy, 36, 1620-1634.

Cummings, W. K., \& Finkelstein, H. J. (2012). Scholars in the changing American academy. New contexts, new rules and new roles. Dordrecht: Springer.

Deardorff, D. K., de Wit, H., Heyl, J. D., \& Adams, T. (2012). The SAGE handbook of international higher education. Los Angeles: Sage.

de Wit, H. (2002). Internationalization of higher education in the United States of America and Europe. Westport, CT: Greenwood Press.

Finkelstein, M. J., Walker, E., \& Chen, R. (2013). The American faculty in an age of globalization: Predictors of internationalization of research content and professional networks. Higher Education, 66, 325-340.

Georghiou, L. (1998). Global cooperation in research. Research Policy, 27, 611-628.

Glaser, B. G. (1963). The local-cosmopolitan scientist. The American Journal of Sociology, 69, 249-259.

Gouldner, A. (1957). Cosmopolitans and locals: Toward an analysis of latent social roles-I. Administrative Science Quarterly, 2, 281-306. 
Grimes, A. J. (1980). Cosmopolitan-local: A multidimensional construct. Research in Higher Education, 13, 195-211.

Harman, K. M. (1989). Professional loyalties of university academics: Four ideal types. Australian Educational Review, 16(2), 1-11.

Hoekman, J., Frenken, K., \& Tijssen, R. J. W. (2010). Research collaboration at a distance: Changing spatial patterns of scientific collaboration within Europe. Research Policy, 39, 662-673.

Huang, F., Finkelstein, M., \& Rostan, M. (2014). The internationalization of the academy: Changes, realities and prospects. Dordrecht, The Netherlands: Springer.

Jeong, S., Choi, J. Y., \& Kim, J.-Y. (2011). The determinants of research collaboration modes: Exploring the effects of research and researcher characteristics on co-authorship. Scientometrics, 89, 967-983.

Jeong, S., Choi, J. Y., \& Kim, J.-Y. (2014). On the drivers of international collaboration: The impact of informal communication, motivation, and research resources. Science and Public Policy, 41, 520-531.

Jung, J., Kooij, R., \& Teichler, U. (2014). Internationalization and the new generation of academics. In F. Huang, M. Finkelstein, \& M. Rostan (Eds.), The internationalization of the academy: Changes, realities and prospects (pp. 207-236). Dordrecht, The Netherlands: Springer.

Katz, J. S., \& Martin, B. R. (1997). What is research collaboration? Research Policy, 26, 1-18.

Knight, J. (2010). Internationalization and the competitiveness agenda. In L. M. Portnoi, V. D. Rust, \& S. S. Bagley (Eds.), Higher education, policy, and the global competition agenda (pp. 205-218). New York, NY: Palgrave Macmillan.

Knight, J. (2012). Concepts, rationales, and interpretive frameworks in the internationalization of higher education. In D. K. Deardorff, H. de Wit, J. Heyl, \& T. Adams (Eds.), The SAGE handbook of international higher education (pp. 27-42). Los Angeles, CA: Sage.

Kwiek, M. (2012). Changing higher education policies: From the deinstitutionalization to the reinstitutionalization of the research mission in polish Universities. Science and Public Policy, 35(5), 641-654.

Kwiek, M. (2015a). The internationalization of research in Europe. A quantitative study of 11 national systems from a micro-level perspective. Journal of Studies in International Education, 19(2), 341-359.

Kwiek, M. (2015b). The unfading power of collegiality? University governance in Poland in a European comparative and quantitative perspective. International Journal of Educational Development, 43, 77-89.

Kwiek, M. (2015c). Academic generations and academic work: Patterns of attitudes, behaviors and research productivity of Polish academics after 1989'. Studies in Higher Education, 40(8), 1354-1376.

Kwiek, M. (2016). The European research elite: A cross-national study of highly productive academics across 11 European systems. Higher Education, 71(3), 379-397.

Kwiek, M. (2017a). Academic top earners. Research productivity, prestige generation and salary patterns in European Universities. Science and Public Policy. 1-13. scx020, https://doi. org/10.1093/scipol/scx020.

Kwiek, M. (2017b). A generational divide in the polish academic profession. A mixed quantitative and qualitative approach. European Educational Research Journal, 17, 1-26.

Kyvik, S., \& Aksnes, D. W. (2015). Explaining the increase in publication productivity among academic staff: A generational perspective. Studies in Higher Education, 40, 1438-1453. 
Kyvik, S., \& Larsen, I. M. (1994). International contact and research performance. Scientometrics, 29(1), 161-172.

Kyvik, S., \& Larsen, I. M. (1997). The exchange of knowledge: A small country in the international research community. Science Communication, 18, 238-264.

Landry, R., \& Amara, N. (1998). The impact of transaction costs on the institutional structuration of collaborative academic research. Research Policy, 27, 901-913.

Laudel, G. (2002). What do we measure by co-authorships? Research Evaluation, 11, 3-15.

Lee, S., \& Bozeman, B. (2005). The impact of research collaboration on scientific productivity. Social Studies in Science, 35, 673-702.

Lewis, J. M. (2013). Academic governance: Disciplines and policy. New York, NY: Routledge.

Lewis, J. M., Ross, S., \& Holden, T. (2012). The how and why of academic collaboration: Disciplinary differences and policy implications. Higher Education, 64, 693-708.

Luukkonen, T., Persson, O., \& Sivertsen, G. (1992). Understanding patterns of international scientific collaboration. Science, Technology, \& Human Values, 17, 101-126.

Marquina, M., \& Jones, G. (2015). Generational change and academic work: An introduction. Studies in Higher Education, 40, 1349-1353.

Melin, G. (2000). Pragmatism and self-organization: Research collaboration on the individual level. Research Policy, 29, 31-34.

Melin, G., \& Persson, O. (1996). Studying research collaboration using co-authorships. Scientometrics, 36, 363-377.

Merton, R. K. (1973). Multiple discoveries as strategic research site. In R. K. Merton (Ed.), The sociology of science: Theoretical and empirical investigations (pp. 371-382). Chicago, IL: University of Chicago Press.

Narin, F., \& Whitlow, E. S. (1990). Measurement of scientific co-operation and coauthorship in CEC-related areas of science. Luxembourg: European Communities.

Porter, C. O. L. H., Itir Gogus, C., \& Yu, C.-F. (2010). When does teamwork translate into improved team performance? A resource allocation perspective. Small Group Research, 41, 221-248.

Rhoades, G., Kiyama, J. M., McCormick, R., \& Quiroz, M. (2008). Local cosmopolitans and cosmopolitan locals: New models of professionals in the academy. The Review of Higher Education, 31, 209-235.

RIHE. (2008). The changing academic profession over 1992-2007: International, comparative, and quantitative perspective. Research Institute for Higher Education, Hiroshima, Japan: Author.

Rostan, M., \& Ceravolo, F. A. (2015). The internationalization of the academy: Convergence and divergence across disciplines. European Review, 23(Suppl. 1), S38-S54.

Rostan, M., Ceravolo, F. A., \& Metcalfe, S. A. (2014). The internationalization of research. In F. Huang, M. Finkelstein, \& M. Rostan (Eds.), The internationalization of the academy: Changes, realities and prospects (pp. 119-144). Dordrecht, The Netherlands: Springer.

Rostan, M., Finkelstein, M., \& Huang, F. (2014). A Profile of CAP Participating Countries and a Global Overview of Academic Internationalization in 2007-2008. In F. Huang, M. Finkelstein, \& M. Rostan (Eds.), The internationalization of the academy. Changes, realities and prospects (pp. 37-54). Dordrecht: Springer.

Shin, J. C., Arimoto, A., \& Cummings, W. K. (2014). Teaching and research in contemporary higher education: Systems, activities and rewards. Dordrecht, The Netherlands: Springer.

Smeby, J.-C., \& Gornitzka, A. (2008). All cosmopolitans now? The changing international contacts of university researchers. In Å. Gornitzka \& L. Langfeldt (Eds.), Borderless 
knowledge: Understanding "new" internationalisation of research and higher education in Norway (pp. 37-50). Dordrecht, The Netherlands: Springer.

Smeby, J. C., \& Trondal, J. (2005). Globalisation or Europeanisation? Stratification of international contact among university staff. Higher Education, 49, 449-466.

Teichler, U., Arimoto, A., \& Cummings, W. K. (2013). The changing academic profession: Major Findings of a comparative survey. Dordrecht, The Netherlands: Springer.

Teichler, U., \& Höhle, E. E. (Eds.). (2013). The work situation of the academic profession in Europe: Findings of a survey in twelve countries. Dordrecht, The Netherlands: Springer.

Wagner, C. S. (2006). International collaboration in science and technology: Promises and pitfalls. In L. Box \& R. Engelhard (Eds.), Science and technology policy for development: Dialogues at the interface (pp. 165-176). London, England: Anthem Press.

Wagner, C. S., \& Leydesdorff, L. (2005). Network structure, self-organization, and the growth of international collaboration in science. Research Policy, 34, 1608-1618.

Welch, A. (1997). The peripatetic professor: The internationalization of the academic profession. Higher Education, 34, 323-345.

Whitley, R. (1984). The intellectual and social organization of the sciences. Oxford, UK: Oxford University Press.

\section{Author Biography}

Marek Kwiek holds UNESCO Chair in Institutional Research and Higher Education Policy at the University of Poznan, Poland. His research interests include the academic profession and higher education governance and funding. An editorial board member of Higher Education Quarterly, European Educational Research Journal, British Educational Research Journal and European Journal of Higher Education. Contact: kwiekm@amu.edu.pl, www.cpp.amu.edu.pl. 